\title{
ТРЕТЬЯ ФУНКЦИЯ УНИВЕРСИТЕТА: ПОТРЕБНОСТЬ ИЛИ ОБЯЗАННОСТЬ
}

\author{
Н.В. Мальковец \\ Новокузнеикий институт (филиал) \\ Кемеровского государственного университета, Новокузнеик, Россия, \\ e-mail:n_malkovets@mail.ru
}

Статья посвящена третьей функции университета (вуза), связанной с взаимодействием с обществом, в том числе местным сообществом, властью и бизнесом, дополняющей образовательную и научно-исследовательскую функции. Автор поднимает такие проблемы, как непонимание сущности и важности третьей функции среди преподавателей и руководителей образовательных учреждений, отсутствие сформированной потребности и мотивации для развития взаимодействия, нормативных актов, обязывающих образовательное учреждение интегрироваться в местное сообщество, и другие. Между тем реализация третьей функции открывает новые возможности для научной, исследовательской, педагогической и образовательной деятельности вуза. Научная и практическая работа автора позволили сформулировать рекомендации для дальнейшего развития третьей функции университета: создание центра, изучение успешного опыта, проведение проектных сессий, объединение наиболее активных вузов для защиты своих прав и т.д.

Ключевые слова: университет, третья функиия, взаимодействие, общество, власть, город.

\section{THE THIRD FUNCTION OF THE UNIVERSITY: THE NEED OR THE DUTY}

\author{
N.V. Malkovets
}

\section{Novokuznetsk Branch of Kemerovo State University, Novokuznetsk, Russia e-mail:n_malkovets@mail.ru}

Article is devoted to the third function of the university (higher education institution) connected with interaction with society, including, local communities, the governments and business supplementing such functions as educational and scientific research. The author lifts such problems as misunderstanding of essence and importance of the third function among teachers and heads of educational institutions, lack of the created requirement and motivation for development of the interaction, the regulations obliging educational institution to be integrated into local community, and others. Meanwhile, realization of the third function opens new opportunities for scientific, research, pedagogical and educational activity of 
higher education institution. Scientific and practical work of the author allowed to formulate recommendations for further development of the third function of the university: creation of the center, studying of successful experience, holding design sessions, association of the most active higher education institutions for protection of the rights, etc.

Keywords: university, the third function, collaboration, society, governments, city.

\section{DOI 10.14258/ssi(2019)3-6282}

Основная задача высшей школы - подготовка кадров. Не менее важной является научно-исследовательская функция университетов. Существует еще и третья функция (Ицковиц, 2010). Она связана с влиянием университета на социум - общество и общественные отношения, с подготовкой студентов к жизни в гражданском обществе, умением оказывать влияние на общественную и политическую жизнь, совмещением обучения и общественно-полезной деятельности, получением знаний через практику, приобретением партнеров и полезного жизненного опыта.

Среди множества проблем, опасений, негативных прогнозов, которые высказываются на кафедрах, в сетях, на конференциях и в частных разговорах о ситуации, складывающейся в системе высшего образования, можно выделить такую проблему, как формальное, необдуманное и заведомо неэффективное планирование и реализация вузом задачи инновационного социального развития территории. Давайте разберемся, каким образом это связано с третьей функцией университетов.

Совсем недавно в нашей стране появился новый тип образовательного учреждения высшего образования — опорный вуз. Проект Министерства образования и науки Российской Федерации «Опорные университеты» имеет своей целью отбор проектов программ развития, направленных на формирование опорных университетов в целях социально-экономического развития субъектов Российской Федерации. В том числе это планируется осуществить за счет создания университетских центров инновационного, технологического и социального развития регионов. В требованиях к разрабатываемым участниками конкурса проектам программы развития опорного университета назван такой критерий, как наличие мероприятий по развитию местных сообществ, городской и региональной среды ${ }^{1}$.

Однако среди показателей, характеризующих деятельность опорного университета в рамках реализации программы развития, кроме удельного веса «численности обучающихся (приведенного контингента) по проектно-ориентированным образовательным программам инженерного, медицинского, социально-экономического, педагогического естественно-научного и гуманитарного профилей, предполагающих командное выполнение проектов полного жизненного цикла, в общей численности обучающихся (приведенного контингента)» нами не найдено ничего иного, что могло бы более конкретно характеризовать деятельность вуза по развитию местных сообществ, городской и региональной среды. Хотя, разумеется, сту-

\footnotetext{
1 Сайт Проекта Министерства образования и науки Российской Федерации «Опорные университеты». URL:http://опорныйуниверситет.pф/about (дата обращения 13.07.2019).
} 
денты всех вышеперечисленных направлений могут успешно и с пользой взаимодействовать с региональной средой и местным сообществом, а проектный подход для социально-экономического развития территории необычайно важен.

Отсюда возникают требования к преподавателям и сотрудникам вуза как результат неверно понятой задачи: капитализация результатов гуманитарных исследований; включенность в жизнь местных сообществ, когда эту многообразную жизнь никто в вузе не изучал; участие в разработке программ и стратегий развития территории без имеющихся необходимых для этого компетенций и т.д.

Между тем третья функция, или «третья миссия», университетов известна и реализуется задолго до того, как в нашей стране возникли опорные вузы (Бахмин, 2017).

Суть этой функции в том, что кроме традиционно закрепленных за вузами в качестве основных таких функций обучения и научно-исследовательской деятельности возникает социальная функция. И возникает она не как обязанность, а как необходимость и потребность. И это достаточно широкий спектр деятельности: некоммерческие проекты, направленные на решение социальных проблем сообщества; новая стратегия в направлении непрерывного образования, трансфера технологий и развития инноваций; вовлеченность университетов в социальную жизнь, предпринимательство и т.д. Третья - социальная миссия университета предполагает активное участие высшей школы в жизни общества.

Практический опыт и история европейских вузов показывают, что таким образом университеты создают запас доверия к себе, выступая в качестве компетентного некоммерческого партнера, чем привлекают абитуриентов, а также используют полученный практический опыт социального партнерства при организации научных исследований и в процессе обучения. Студенты, в свою очередь, в процессе внеаудиторной деятельности взаимодействуя с институтами гражданского общества и органами власти, имеют возможность применить академические знания, получить дополнительную квалификацию, сформировать новые гражданские компетенции. В конце концов, понять, что происходит вне стен академического учреждения. Общественная активность не только готовит студента к будущей профессиональной деятельности, но также способствует развитию личности обучаемого, развивает его коммуникативные компетенции, формирует навыки ответственного поведения в обществе, воспитывает гражданина. Международный опыт убедительно демонстрирует, насколько продуманное и активное взаимодействие вуза с местным сообществом может изменить жизнь университета и его восприятие в обществе.

В современной России первыми вузами, инициировавшими собственное взаимодействие с регионом и местным сообществом, стали региональные вузы и их филиалы в муниципальных образованиях.

Здесь можно вспомнить, что в 1990-е гг. в разы увеличилось количество высших учебных заведений в региональных столицах и нестоличных городах. Эти образовательные учреждения стали восприниматься как точки роста, как партнеры власти и общества, способные обеспечить инновационность развития территории, кластерный подход, как гарантия сохранения и развития кадрового и человеческого потенциала. 
В 2010-2012 гг. нами в составе рабочей группы была проделана огромная работа по сбору и описанию успешных практик учебно-исследовательской деятельности региональных университетов, которая базируется на местных ресурсах и потребностях и связана с взаимодействием с местными сообществами. В ходе этой работы были отобраны и проанализированы сайты более 200 вузов из 70 городов Урала и Сибири - от Челябинска, Магнитогорска, Екатеринбурга и Миасса на западе до Ангарска, Комсомольска-на-Амуре и Хабаровска на востоке. Анализ показал достаточно высокую степень потребности вузов в деятельности, связанной с третьей функцией: образовательные и просветительские проекты; консультационные центры по вопросам поддержки и развития малого предпринимательства; развитие волонтерской деятельности и добровольчества; воспитание толерантности; участие в формировании стратегии социально-экономического развития территории; обсуждение важных вопросов жизнедеятельности; поддержка гражданских инициатив; организация молодежного самоуправления и общественного движения; школы социального проектирования; развитие внутреннего туризма; участие в экологических акциях, например по решению вопросов обращения с отходами, и многое другое.

С сожалением надо признать, что большинство из этих инициатив сегодня прекратили свое существование. Одни - в связи с оптимизацией вуза, другие в связи с сокращением профессорско-преподавательского состава.

Новокузнецкий филиал (а затем - институт) Кемеровского госуниверситета изначально создавался с идеей «город вокруг университета». И, когда в конце 1990-х гг. мы начали готовить специалистов (позднее - бакалавров) для государственного и муниципального управления, мы сразу приняли концепцию гражданского образования на основе знаний о местном самоуправлении. Она была официально признана ученым советом вуза. Мы понимали, что не все наши выпускники смогут работать в органах власти. Но, будучи активными и просвещенными гражданами, обладая необходимыми гражданскими компетенциями и активной жизненной позицией, они будут востребованы в обществе и на рынке, смогут самостоятельно организовать рабочее место (например, создавая ТСЖ в своем многоквартирном доме, малое предприятие и т.д.) либо обеспечить себе занятость в некоммерческом секторе (Мальковец, 2006). Сегодня эта работа продолжается только благодаря нескольким преподавателям-энтузиастам.

Некоторые российские фонды и некоммерческие организации проводят большую работу по разъяснению сущности третьей функции университетов и распространению лучших практик. Например, в ноябре 2017 г. в рамках Общероссийского гражданского форума, организованного Комитетом гражданских инициатив, прошла дискуссия «Третья миссия университетов», в которой приняли участие представители вузов, имеющих опыт такой деятельности, в том числе автор настоящей статьи. Состоялся серьезный разговор об успехах и ошибках вузов в этом направлении. Например, нам был задан вопрос: «Кто ваш заказчик?»1․

На этот вопрос нельзя ответить однозначно. Напрашивается мысль: а если нет заказчика - что, эта деятельность не может вестись?

\footnotetext{
${ }^{1}$ Дискуссия «Третья миссия университетов». URL: https://www.youtube.com/watch?v=9eNZU3WVRrA (дата обращения 13.02.2018).
} 
На практике, конечно, не всегда мы работаем pro bono, хотя сама «третья функция» для нас первична, как насущная потребность. Впоследствии может появиться и заказчик. Так в ряде сибирских вузов при поддержке органов власти появились «Точки кипения» - студенческие бизнес-инкубаторы ${ }^{1}$.

Есть и другие возможности. Во-первых, такая работа может вестись в рамках гранта. В НФИ КемГУ, например, было реализовано два гранта, выделенных в разное время Фондом «Новая Евразия» специально для развития взаимодействия университетов и местных сообществ.

Во-вторых, это может быть работа в рамках гранта, полученного партнерской организацией. Это хорошая возможность для развития волонтерства и добровольчества в вузе, обучения студентов навыкам такой деятельности. Такой опыт у нас также имеется и он показал свою эффективность (Зубарева, Мальковец, 2018). Среди наших партнеров - органы власти всех уровней, некоммерческие организации, активные жители и лидеры территориального общественного самоуправления, другие образовательные учреждения (школы, техникумы и пр.), крупные промышленные предприятия и корпорации, реализующие программы корпоративной социальной ответственности, представители самых различных городов и регионов 2 .

Наконец, это работа в рамках учебной дисциплины, совмещение обучения с общественно-полезной деятельностью. Конечно, для этого требуется специальная подготовка педагогов, их активная гражданская позиция. В нашей работе показали свою эффективность мастер-классы, которые проводят представители власти, активные жители, внешние эксперты и лидеры некоммерческих организаций. Работа с кейсами, анализ реальных ситуаций, междисциплинарные исследования социальных и инфраструктурных проблем города и, конечно, форсайты, проектные тренинги и практикумы (Мальковец, 2014). Мы в течение нескольких лет проводили междисциплинарное научное исследование «Трамвай vs Троллейбус», которое оказало влияние на позицию органов местного самоуправления города Новокузнецка при принятии решений, связанных с развитием экологического транспорта.

До сих пор мы имели в виду ситуации, когда вуз инициирует взаимодействие с сообществом. А может ли сообщество инициировать такое взаимодействие? На самом деле в местном сообществе всегда происходит много интересного, в чем представителям вуза полезно принять участие. Однажды к нам обратился предприниматель, который хотел бы собрать активных горожан и обсудить проблемы, существующие в городе. В результате возник клуб «Диалоги о городе», в котором принимают участие представители разных вузов и других образовательный учреждений, и появилась идея создания общественной стратегии развития города. В этой работе

${ }^{1}$ Сайт Ассоциации выпускников HTTУ. URL: https://assoc.nstu.ru/\%D0\%BE\%D1\%82\%D0\%BA\%D1 $\% 80 \% \mathrm{D} 1 \% 8 \mathrm{~B} \% \mathrm{D} 1 \% 82 \% \mathrm{D} 0 \% \mathrm{~B} 8 \% \mathrm{D} 0 \% \mathrm{~B} 5-\% \mathrm{D} 1 \% 82 \% \mathrm{D} 0 \% \mathrm{BE} \% \mathrm{D} 1 \% 87 \% \mathrm{D} 0 \% \mathrm{BA} \% \mathrm{D} 0 \% \mathrm{~B} 8-\% \mathrm{D} 0 \% \mathrm{~B}$ A $\%$ D0\%B8\%D0\%BF\%D0\%B5\%D0\%BD $\%$ D0 $\%$ B8 $\%$ D $1 \% 8 \mathrm{~F}-\% \mathrm{D} 1 \% 81 \% \mathrm{D} 1 \% 82 \% \mathrm{D} 1 \% 83 \% \mathrm{D} 0 \% \mathrm{~B} 4 \% \mathrm{D}$ 0\%B5\%D0\%BD\%D1\%87\%D0\%B5\%D1\%81\%D0\%BA\%D0\%BE\%D0\%B3/

( ата обращения 23.07.2019).

2 Сеть «Взаимодействие вуза с партнерами и местным сообществом» (Группа в ФБ). URL: https:// www.facebook.com/groups/ (дата обращения 17.07.2019). 
сейчас принимают участие и преподаватели, и студенты, активные жители, среди которых предприниматели, работники культуры, журналисты и пр. Очень часто мы откликаемся на просьбы и конкретный заказ органов местного самоуправления. Одно из последних мероприятий — форсайт «Умный дом в Новокузнецке», в котором приняли участие студенты - будущие программисты, управленцы, социологи, экологи, представители администрации города, активные жители и руководители управляющих организаций. Формирование видения будущего многоквартирного дома, связанного с цифровизацией, позволило сформулировать конкретные рекомендации для всех заинтересованных сторон.

Что же можно порекомендовать опорному вузу, не имеющему пока опыта реализации социальных проектов?

Конечно, такая деятельность должна быть институционализирована. Министерство образования и науки Российской Федерации рекомендует создавать университетские центры. Практика показывает, что содержание вузом такого центра часто приходит в противоречие с задачей оптимизации расходов. Если же принято решение о его создании, нам кажется, что хорошим началом для работы такого центра (или инициативной группы) могла бы быть проектная сессия. Возможно, ее необходимо организовывать с помощью более опытных коллег. Сессия может объединить различные ресурсы, уже имеющиеся в вузе. Например, в Новосибирске и Екатеринбурге преподаватели-филологи вместе с активистами кафедры менеджмента реализовали просветительский проект для любителей русского языка. В результате были изданы и размещены в общественном транспорте листовки с указанием правильного ударения в таких словах, в которых люди чаще всего делают ошибки. В частности пассажиры метро во время поездки имели возможность освежить свои знания и были весьма благодарны авторам.

В каждом вузе есть ученые и исследователи, имеющие уникальные знания, с одной стороны, и те, кто обладает фантазией, умеет придумать что-то интересное и креативное, с другой стороны. Есть еще и те, кто учится зарабатывать деньги, находить инвестора, создавать финансовую структуру. Объединив эти компетенции, можно реализовать интереснейшие проекты, повысить авторитет своего вуза, сделать массу полезных дел для своей малой родины.

Другая рекомендация касается того, что вузам, для которых третья функция давно уже стала потребностью, а не обязанностью, необходимо объединиться для защиты своих позиций. Здесь возникает такая парадоксальная ситуация, связанная с тем, что мы учим активных граждан, органы местного самоуправления, жителей объединяться для защиты своих прав. При этом сами мы, во-первых, плохо знаем друг друга и не обмениваемся опытом, во-вторых, у нас нет ассоциации. Между тем зарубежные вузы, осуществляющие взаимодействие с местным сообществом, объединены в сеть, которая называется Talloires Network ${ }^{1}$.

Подобное российское объединение, на наш взгляд, могло бы сделать очень многое для повышения авторитета вузов, признания этой деятельности Мини-

1 Talloires Network Newsletter URL: http://mailchi.mp/5062b02c6e19/talloires-network-newsletter1263789https://komitetgi.ru/analytics/3402/ (дата обращения 23.10.2017). 
стерством образования РФ, например, добившись введения такого аккредитационного показателя для регионального вуза, как взаимодействие с местным сообществом.

Таким образом, нами сделана попытка обосновать свою позицию и доказать, что третья функция университета должна стать и потребностью, и обязанностью. Потребностью - через бережное отношение и поддержку разовых инициатив, обязанностью - через создание нормативной базы, создающей условия и способствующей развитию третьей функции университета.

\section{БИБЛИОГРАФИЧЕСКИЙ СПИСОК}

Бахмин В.И. Вузы и местные сообщества - инструмент инновационного развития регионов. Комитет гражданских инициатив. URL: https://komitetgi.ru/analytics/3402/ (дата обращения 23.10.2017).

Гордиенко А.А. Гражданская активность и инновационное развитие региона. Новосибирск, 2014.

Зубарева Т.А., Мальковец Н.В. (ред). Взаимодействие вуза с партнерами для повышения конкурентоспособности студентов: сб. материалов сетевого методического тренинга по теме «Проектирование взаимодействия вуза с партнерами и участия в местном самоуправлении для повышения конкурентоспособности студентов», 24-27 сент. 2014 г. Новокузнецкий институт (филиал) Кемеровского государственного университета. Новокузнецк, 2014.

Зубарева Т.А., Мальковец Н.В. (ред). Диалоги о главном. Свой город. Междуреченск, 2018.

Зубарева Т.А., Мальковец Н.В. Создание сети взаимодействия вуза с партнерами для освоения проектной составляющей в профессии. Вестник Кемеровского государственного университета. Серия: Гуманитарные и общественные науки, 2018; (1): 15-21. doi/10.21603/2542-1840-2018-1-15-21.

Ицковиц Г. Тройная спираль. Университеты - предприятия - государство. Инновации в действии. Томск: Изд-во Томск. гос. ун-та систем управления и радиоэлектроники, 2010 .

Мальковец Н.В. Гражданское образование студентов вуза. Кемерово; М. Российские университеты, 2006.

Демчук Н.В., Басалаева И.П. (ред). Университет и сообщество в индустриальном городе: сб. материалов. Новокузнецк, 2013.

\section{REFERENCES}

Bahmin, V.I. (2017). Vuzy i mestnye soobshhestva - instrument innovacionnogo razvitija regionov. [Higher education institutions and local communities - the instrument of innovative development of regions]. Komitet grazhdanskih iniciativ. Available at: https:// komitetgi.ru/analytics/3402/ (accessed 23 October 2017). 
Gordienko, A.A. (2014). Grazhdanskaja aktivnost'i innovacionnoe razvitie regiona [Civil activity and innovative development of the region]. Novosibirsk.

Zubareva, T.A., Malkovets, N.V. (2014). Vzaimodeistvie vuza s partnerami dl'a povishenija kokurentnosposobnosti studentov: sb. materialov setevogo metodicheskogo treninga po teme «Proektirovanie vzaimodeistvija vuza s partnerami i uchastija v mestnom samoupravlenii dlja povishenija kokurentnosposobnosti studentov» [The interaction of the higher education institution with the partners for increasing the competitiveness of students: proc. training materials on a subject: «The interaction project of the higher education institution with the partners and the participation in local government for increasing the competitiveness of students»], 24-27 sept. 2014. Novokuzneckij institut (filial) Kemerovskogo gosudarstvennogo universiteta. Novokuznetsk.

Zubareva, T.A., Malkovets, N.V. (2018). Dialogi o glavnom. Svoj gorod: [The dialogues about the main thing. Own city]. Mezhdurechensk.

Zubareva, T.A., Malkovets, N.V. (2018). Sozdanie seti vzaimodejstvija vuza s partnerami dlja osvoenija proektnoj sostavljajushhej v professii [Creation of the network of the interaction of higher education institution with the partners for the development of the project component in the professoin]. Vestnik Kemerovskogo gosudarstvennogo universiteta, [Bulletin of the Kemerovo State University]. Serija: Gumanitarnye i obshhestvennye nauki, no (1), 15-21. doi/10.21603/2542-1840-2018-1-15-21.

Ickovic, G. (2010). Trojnaja spiral. Universiteti - predprijatija - gosudarstvo. Innovatsii v deistvii [Threefold spiral. The universities - the enterprises - the state. Innovations in the operation]. Tomsk: Izd-vo Tomsk. gos. un-ta system upravleniya i radioelektroniki.

Malkovets, N.V. (2006). Grazhdanskoe obrazovanie studentov vuza [Civic education of students of higher education institution] Kemerovo; M.: Rossijskie universitety.

Demchuk, N.V., Basalaeva, I.P. (2013). Universitet $i$ soobshhestvo v industrial'nom gorode [The university and community in the industrial city]: sb.materialov (po materialam proekta «Universitet i soobshhestvo»). Novokuznetsk. 